\title{
A survey-based analysis of the public's willingness for disaster relief in China
}

\author{
Zewen $\mathrm{Hu}^{1}$ (D) Xiaocai Zhang ${ }^{1,3} \cdot$ Jingjing Cui ${ }^{1} \cdot$ Lijie Zhang $^{1} \cdot$ Wasim Ahmed $^{2}$ (D)
}

Received: 1 June 2020 / Accepted: 16 January 2021 / Published online: 3 February 2021

(c) The Author(s) 2021

\begin{abstract}
Meteorological disasters frequently occur in China and around the world. These natural hazards can cause huge economic losses and threaten the personal safety of citizens. The public's willingness to engage with disaster relief efforts and the degree of participation is critical to reduce the impact of such disasters. This study conducted a survey with 62,903 respondents from China. The study utilized statistical analysis and correlation analysis in order to understand the differences and similarities of the public's willingness to take part in disaster relief across gender and age. The study found that: (1) the public's awareness of insurance and willingness to make donations during climate disasters is low, and that more than half of the public are only willing to insure for very less money; (2) although the public has very high enthusiasm to participate in disaster relief, they are less willing to learn the basic skills of reducing disasters and for participating in training for disaster reduction as volunteers. This was especially the case for elderly citizens and females; (3) the willingness of the public to prevent and reduce disasters is high, and this was the case across various gender and age groups. Finally, the study puts forward several measures to improve the uptake of disaster relief and disaster prevention among citizens.
\end{abstract}

Keywords Meteorological disasters · Willingness of disaster relief · Quantitative analysis · Disaster prevention - Insurance and donation

Wasim Ahmed

Wasim.ahmed@newcastle.ac.uk

Zewen $\mathrm{Hu}$

huzewen915@163.com

Xiaocai Zhang

20151307017@nuist.edu.cn

Jingjing Cui

jingjingcui0528@163.com

Lijie Zhang

lijiezh@163.com

1 School of Management Science and Engineering, Nanjing University of Information Science and Technology, Nanjing 210044, People's Republic of China

2 Newcastle University Business School, Newcastle University, Newcastle NE1 7RU, UK

3 Faculty of Management and Economics, Kunming University of Science and Technology, Kunming 650093, People's Republic of China 


\section{Introduction}

Meteorological disasters can generally be divided into two categories; the first category is weather and meteorological disaster events such as typhoons, rainstorms, and floods. The second category is meteorological secondary disasters and derivative disaster events such as mudslides and landslides. These multi-hazard risk events have frequently occurred in China and other countries across the world. These events lead to huge economic losses as well as a large number of casualties. According to the statistics from Yearbook of Meteorological Disasters in China (Liu et al. 2018), the average value of direct economic loss between 2004 and 2013 caused by meteorological disasters in China was as much as 305.5 billion Yuan (45.1 Billion USD; $1 \mathrm{CNY}=0.1475$ USD). The largest direct economic losses in 2010 were about 2.5 times of the economic losses in 2004. In 2016, the economic losses caused by meteorological disasters amounted to 503.3 billion Yuan (74.2 Billion USD). Germany has also experienced 85 various natural hazards between 1950 and 2013 including 3 earthquakes, 9 extreme temperature events, 18 floods, and 47 storms. These events have caused more than 10,000 fatalities and nearly 30 billion Euros (35 billion USD) in damage (Kreibich et al. 2014).

According to statistics from the Emergency Events Database (EM-DAT 2020) between 2014 and 2018 there have been 67 storms in China, 74 storms in USA, and 25 storms in Japan which have led to 989, 929, and 201 casualties, respectfully, as well as major monetary losses. Furthermore, the average yearly occurrence frequency and the resulting average economic loss of multi-hazard risk between 2008 and 2018 have been 2.3 times and 1.2 billion in USD for the UK, 3.5 times and 1.5 billion in USD for France, 2.5 times and 3.2 billion in USD for Germany, and 23.4 times and 20.3 billion in USD in China. In 2019, 386 natural disasters have occurred including 160 natural disasters in Asia, 89 natural disasters in Africa, 80 natural disasters in Americas, and 57 natural disasters in Europe. In total this has led to 11,755 deaths, 95 million people have been affected, and 103 billion USD in economic losses have been recorded (Natural disasters 2019). Asia has suffered the highest negative impact and accounting for $40 \%$ of disaster events and $45 \%$ of deaths. India was hit hardest and recorded nearly $20 \%$ of the total deaths. Floods were the deadliest type of disaster accounting for $43.5 \%$ of deaths, followed by extreme temperatures accounting for $25 \%$ of deaths (Natural disasters 2019).

Natural disasters have also seriously affected both normal agricultural production activities and the normal activities of the ecological environment, lives of residents, and industrial production. Since ancient times, agriculture has been the main mode of production in China and has always played an irreplaceable role in the development of China's national economy. At the same time, the proportion of rural areas in China is far greater than that of other countries. However, China's agriculture has frequently been affected by natural hazards such as floods, droughts, winds, frosts, and hail, as well as hazards caused by freezing weather. This has a negative effect on China's grain harvest, food production, and agricultural economy, but also reduces farmers' economic income greatly (Zhong et al. 2014). During 1989-2014, the agricultural areas affected by wind and hail, forest fire, drought, and flood in China are showing significant decreasing trends. However, hazards caused by freezing weather conditions are a trend which has been increasing (Li et al. 2019). Meteorological disasters across the world have caused tremendous impact and damage to the social economy, residents' property, as well as to general health and life. It is, therefore, important to anticipate, plan, and reduce the impact and damage of such disasters. This has 
been an urgent and critical issue faced by governments and organizations from different countries across the world.

At the Third United Nations World Conference in Sendai, Japan, on March 18, 2015, the Sendai Framework for Disaster Risk Reduction 2015-2030 was adopted by the United Nations Office for Disaster Risk Reduction. This framework is the successor instrument to the Hyogo Framework for Action (HFA) 2005-2015: Building the Resilience of Nations and Communities to Disasters (the Hyogo Framework for Action (HFA) 2005-2015 2020). To reduce losses and damages from meteorological disasters the Sendai framework has proposed seven global targets by 2030 . These include substantially reducing global disaster mortality, reducing the number of citizens affected globally, and reducing economic losses in relation to global gross domestic product (GDP). Other targets include the substantial reduction of disaster damage to critical infrastructure and disruption of basic services. Furthermore, the Sendai framework also puts forward a series of guiding principles and priorities for action. The framework notes that disaster risk reduction requires engagement from all of society, and cultural perspectives should be integrated in all policies and practices, as well as women and youth leadership should be promoted. Furthermore, they note that disaster risk reduction should pay special attention to the improvement of organized voluntary work from citizens (the Sendai Framework for Disaster Risk Reduction 2015-2030 2020).

In response to natural hazards, the Japan Meteorological Agency (JMA) has often issued warnings to citizens. However, in some cases there was no effective means of informing municipalities and residents of the risk of an imminent and potentially fatal disaster. In response to this the JMA introduced a system of Emergency Warnings in 2013 to alert people to the significant likelihood of catastrophes. The system would inform residents about all kinds of disaster risk information through various channels across newspaper bulletins, $\mathrm{TV}$, radio, the Internet, and via a loudspeaker among other methods (Emergency Warning System 2013). Much academic research has been conducted over the years into the factors that affect public participation in disaster mitigation and relief. In Western countries, the response of citizens is connected to the flow of information before and during disasters and responses to disasters may vary by religion (Helsloot et al. 2004). Adiyoso and Kanegae (2013), for instance, noted that Islamic values may encourage the public to prevent disasters. Other factors that may encourage the public to prevent disasters include the nature of the disaster scenario itself, the cognition of disaster risks and potential consequences, the costs of disaster reduction (Grothmann et al. 2006; Luo et al. 2013), and geographical factors (O'Neill et al. 2016). Schneider (2011) conducted a review of climate change literature and suggested that an emergency management framework will be helpful for policymakers at all levels. A survey in Pakistan noted that local institutions should engage in disaster preparedness activities (Shah et al. 2019). Yu et al. (2013) suggested that the Chinese government should strengthen public awareness toward climate change and found that people are more willing to take action when they recognize the influence of climate change to daily life. Lin et al (2008) investigated the reasons that flood and landslide victims are less willing to take mitigation measures and found that social trust, risk perception, and social economic are positively associated with mitigation intentions, while psychological vulnerability is negatively associated.

The public's willingness to pay for meteorological disaster prevention is related to the understanding of such disasters and the knowledge of defense measures. An individual's prior experience with insurance and his opinion on the value of insurance as a coping mechanism will influence the decision to obtain it. Citizens in disaster-prone areas may also expect the government to cover losses that are incurred (Wang et al. 2012). Insurance can mitigate residents' costs of evacuation and promote them to actively vacate hazardous 
living conditions as the financial burden of doing so is reduced. McClelland (1993) found that some respondents overestimate the probability of a natural disaster occurring and are more willing to pay for insurance against high loss events. Evacuation costs may act as a constraint on evacuation behavior that could lead to consequences more severe than the loss of a few hundred dollars. Whitehead (2006) examined the demand for private hurricane evacuation insurance. He investigated the feasibility of evacuation insurance for households and their willingness to pay for the insurance to avoid low-risk and low loss hurricane evacuation events. The results indicate that hurricane evacuation insurance would not be a profitable product and the majority of respondents would not purchase the product even the lowest price.

$\mathrm{Xu}$ (2019) summarized four channels of relief funds from the government and suggested that individuals need to improve risk consciousness during disasters and take part in disaster insurance. A survey in Bangladesh found that age, family structure, education, income, and occupation are important determinants for people's willingness to provide voluntary donations and labor (Shahrier et al. 2019). Publicly linked strategies should be advanced by policy makers so that citizens provide more financial support for disasters (Zhang et al. 2019). In addition, other surveys and research have discussed the limitations, schemes, models, and recommendations of insurance to reducing the impacts of disasters on poor people (Hillier 2018), rural farm-household's demand for crop insurance (Arshad et al. 2016; Ngoc et al. 2019), and flood-prone individuals' willingness to buy insurance (Roder et al. 2019). The public's willingness to pay for property-level flood protection (PLEP) is linked to the damage they have suffered and their household income (Owusu et al. 2015).

Furthermore, there are several studies on the assessment of the public's willingness to participate in meteorological disaster mitigation and relief (Juanzon et al. 2018). Samaddar et al (2015) evaluated effective public participation in disaster management based on a case survey in northern Ghana where facilitators are employed for participatory community activities. However, these studies did not specifically analyze what factors affect the public's willingness to engage with disaster relief. Therefore, this study focuses on the specific intention of the public to participate in meteorological disaster mitigation and relief. More specifically, the study aims to examine characteristics and differences across different gender and age groups to develop an understanding of the willingness of the public to engage in disaster relief within China.

\section{Survey design and procedure}

\subsection{Design and procedure of questionnaire}

As shown in Fig. 1, in order to address our research question, we designed a questionnaire that consisted of two parts.

The first part contains personal basic information of respondents including age, gender, education background, and the residence of respondents. The second part contains ten questions related to the disaster relief willingness of the respondents which is summarized in Table 1. The response scale which ranges from A (very willing) to E (unwilling) which was utilized for each of the 10 questions is summarized in Table 2. 


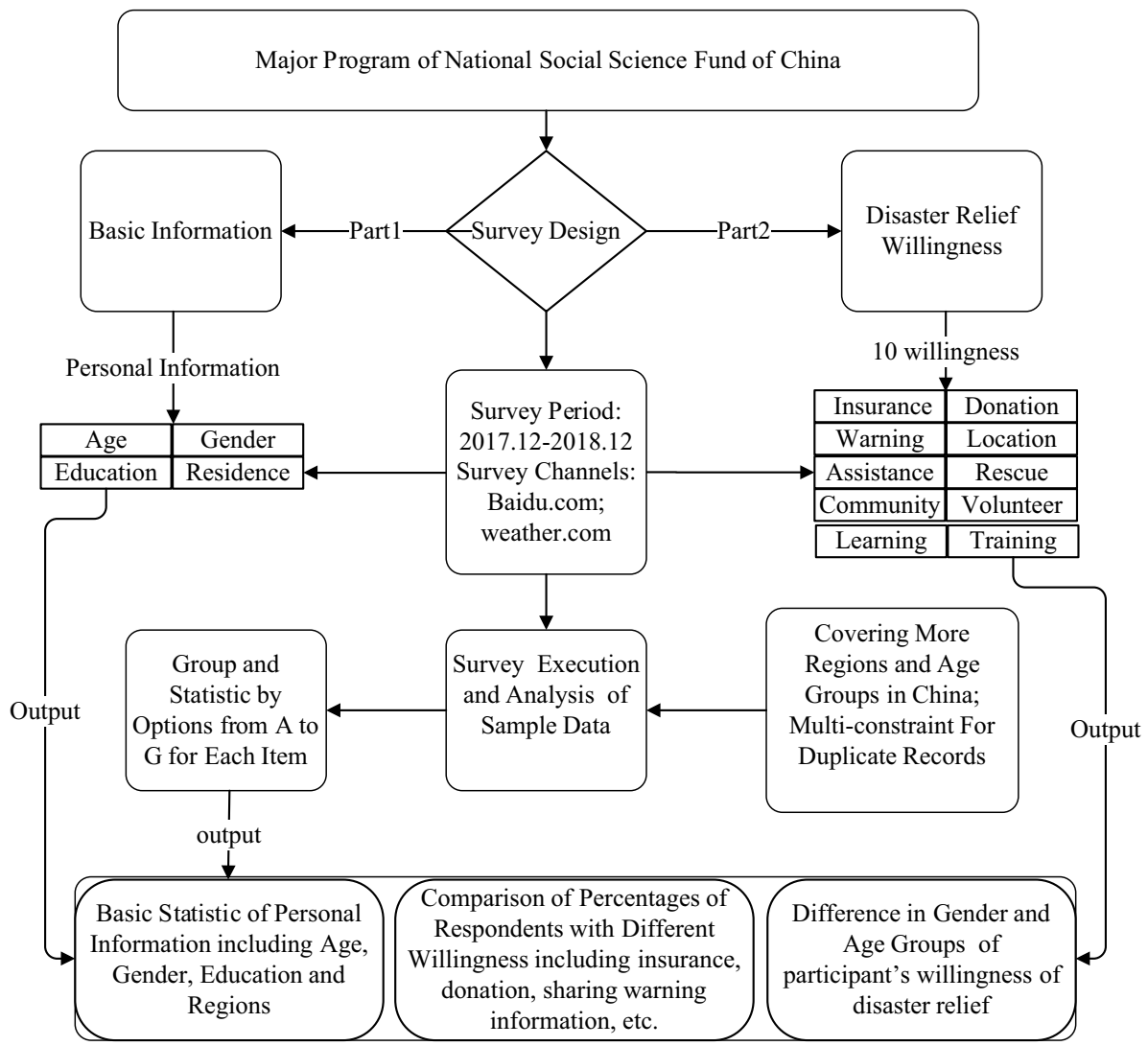

Fig. 1 The basic procedure of survey design and execution

\subsection{Data analysis procedure}

This project collaborated with test.baidu.com and the China Weather Network corporation to complete the survey based on a random sampling technique. In the phase of random sampling, both network investigation and field surveys were utilized. The test.baidu.com and China Weather Network corporation utilized their advantage of big data to randomly distribute questionnaires to a large number of users covering as many regions and age groups as possible and set multi-constraint conditions to avoid duplicate and invalid records. The project was reviewed internally and was deemed ethically low risk. The survey was conducted between December 2017 and December 2018. The final sample of data was obtained from test.baidu.com and the China Weather Network corporation which contains basic information of 62,903 respondents from China and their willingness to take part in natural hazard reduction. Finally, through grouping by options from A to F for each item we conducted a statistical analysis and comparison of the percentages of respondents across gender, age, and different regions. Furthermore, this study conducted a Pearson correlation analysis on the similarities and differences 
Table 1 The public's willingness to engage with disaster relief

Questions related to the readiness of the public to Short title for the question engage with disaster relief

1. How much will you be willing to insure against meteorological disasters?

2. Are you willing to make a donation?

3. Would you like to share disaster warning information to relatives and friends?

4. Are you willing to provide your personal location information to the government's disaster reduction system?

5. Will the government department count the postdisaster material property of your family?

6. Are you willing to take on the work of disaster prevention and self-rescue and mutual rescue?

7. Are you willing to participate in community disaster reduction?

8. Are you willing to be a disaster relief volunteer to help the affected areas?

9. Are you willing to master the basic skills of disaster reduction and rescue?

10. Are you willing to participate in volunteer training for disaster relief in your spare time?
Willingness to insure

Willingness to donate

Willingness to share disaster warning

Willingness to provide location information

Willingness to assist in the statistics

Willingness to take on self-rescue and mutual rescue

Willingness to participate in community disaster reduction

Willingness to volunteer

Willingness to master the basic skills of disaster reduction and rescue

Willingness to participate in volunteer training

of responses across various gender and age groups. Based on this, the issues related the participants' willingness to reduce meteorological disasters were summarized. The survey data were anonymized, and the project was ethically low risk. The Pearson correlation coefficient $r$ is mainly used to judge the linear correlation between two variables. The calculation method is as follows:

$$
r=\left[\sum_{i=1}^{n}\left(x_{i}-\bar{x}\right)\left(y_{i}-\bar{y}\right)\right] / \sqrt{\sum_{i=1}^{n}\left(x_{i}-\hat{\bar{x}}\right) 2\left(y_{i}-\hat{y}\right) 2}
$$

where $n$ is the sample size, and $x_{i}$ and $y_{i}$ are the values of the variables $x$ and $y$. Usually the value range of the correlation coefficient $r$ is $[-1,1]$, if $r$ is a positive value, it means a positive correlation, and a negative number means a negative correlation.

\section{Results}

In total there were 62,903 respondents. It was found that $67 \%$ of the respondents were males, and 33\% were females. The age distribution of respondents is shown in Fig. 2.

As shown in Fig. 2, we can see that most respondents are between 30 and 49 years old (50.7\%), followed by the age group 10-29 (44.8\%) whose proportion is 6\% lower than participants aged $30-49$ years old $(50.7 \%)$, while only a few respondents $(4.5 \%)$ were above 50 years old. 


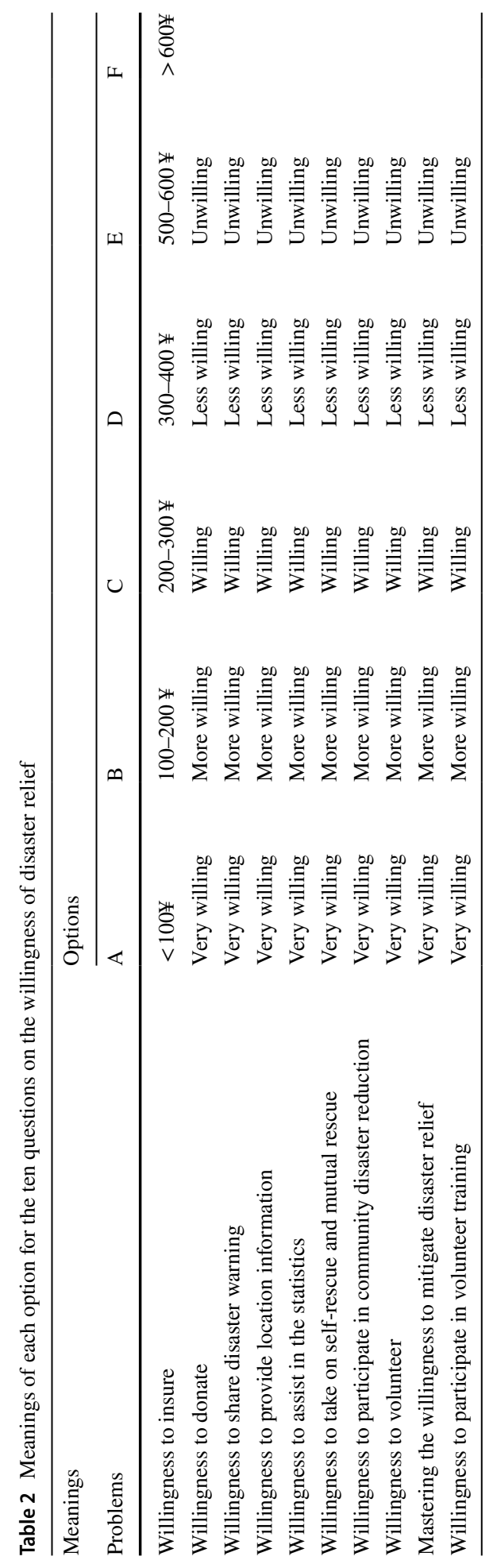


Fig. 2 The age distribution of respondents

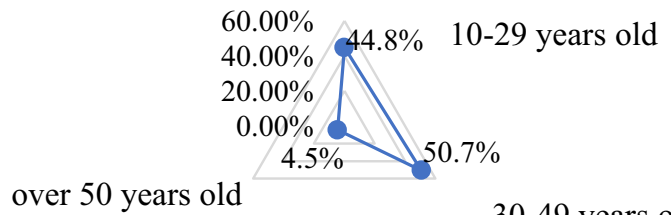

$30-49$ years old

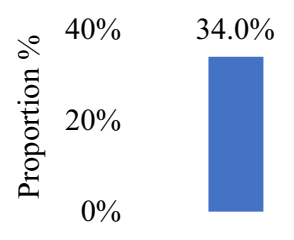

within 100

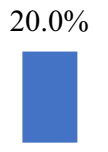

100-200

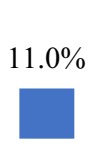

200-300

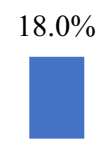

$300-400$

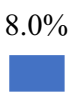

$500-600$
$9.0 \%$

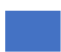

above $600 ¥$

The amount of public insurance

Fig. 3 The percentage of respondents with different amount of insurance

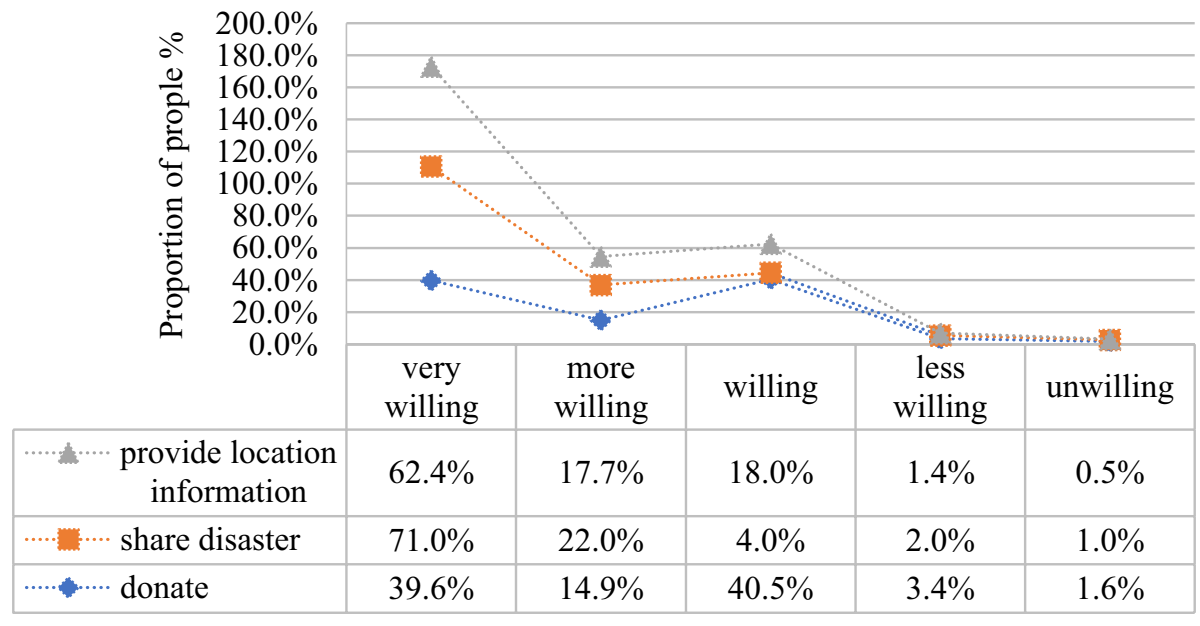

Fig. 4 Participant's willingness to donate money, share warnings, and provide location information

\subsection{Statistical analysis of the public's willingness of disaster relief}

\subsubsection{Public's willingness of insuring to reduce the influence of disaster}

For reducing the impact of a disaster, some residents are willing to pay insurance money to compensate the economic losses caused by disasters. Figure 3 shows the amount of money participants were willing to pay for insurance.

As shown in Fig. 3, most respondents (83\%) were willing to insure within a 400 Yuan (59 USD) price range. It was also found that $34 \%$ of the public were willing to insure within a 100 Yuan price (14.8 USD) range. However, the number of respondents who are willing to insure 500-600 (73.8 to 88.5 USD) and 600 Yuan (88.5 USD) or more accounts 
for the relatively small percentage less than $10 \%$. In addition, almost one-fifth of the public were willing to obtain insurance in the range of 100-200 (14.8 to 29.5 USD) or 300-400 Yuan (44.3 to 59.0 USD).

\subsubsection{Participant's willingness for donating money, sharing warning information, and providing their personal location information}

As shown in Fig. 4, the willingness of participants to donate money once a disaster has occurred is not very positive. Among the respondents in the survey, the proportion of participants who are very willing to donate is less than $40 \%$. Only a few people (5\%) are less willing or unwilling to donate. It was also found that in this scenario $14.9 \%$ of participants are more willing to donate. However, it also shows that participant's willingness to share disaster warning information is very positive, and they are very willing to share warning information with relatives and friends. More respondents (71\%) are very willing to share warning information with relatives and friends. The number of respondents $(22 \%)$ who are more willing to share is also at a good level. The proportion of participants who are less willing and unwilling to share disaster warning information is below 3\%. In addition, participants are likely to provide location information to assist the government in disaster reduction and relief work. More than half of participants are very willing to provide personal location information, and only $1.9 \%$ of participants are less willing or unwilling to provide personal positioning information.

\subsubsection{Participant's willingness to assist, undertake self-rescue and mutual rescue, and participate in community disaster reduction}

Figure 5 shows the participant's willingness to assist government departments to count damage to property and/or affected citizens, undertake disaster prevention, self-rescue and mutual rescue work, and participate in community disaster reduction work.

As shown in Fig. 5, participant's willingness of disaster relief is relatively positive and the public are generally willing to assist the government in post-disaster property statistics.

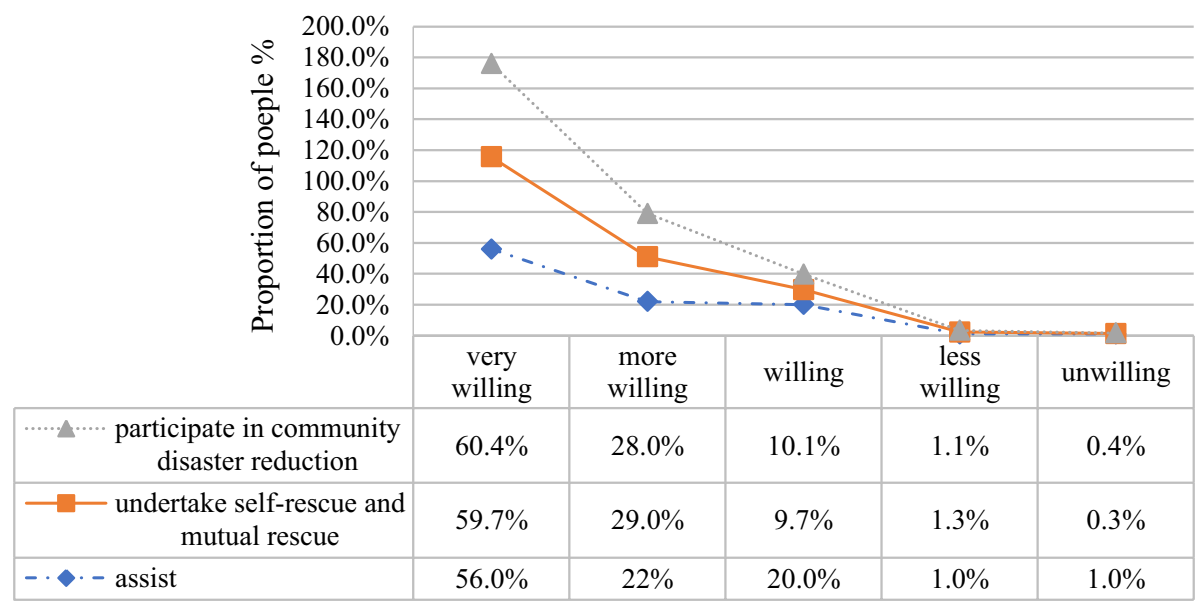

Fig. 5 Participant's willingness to assist, undertake self-rescue, and community disaster reduction 


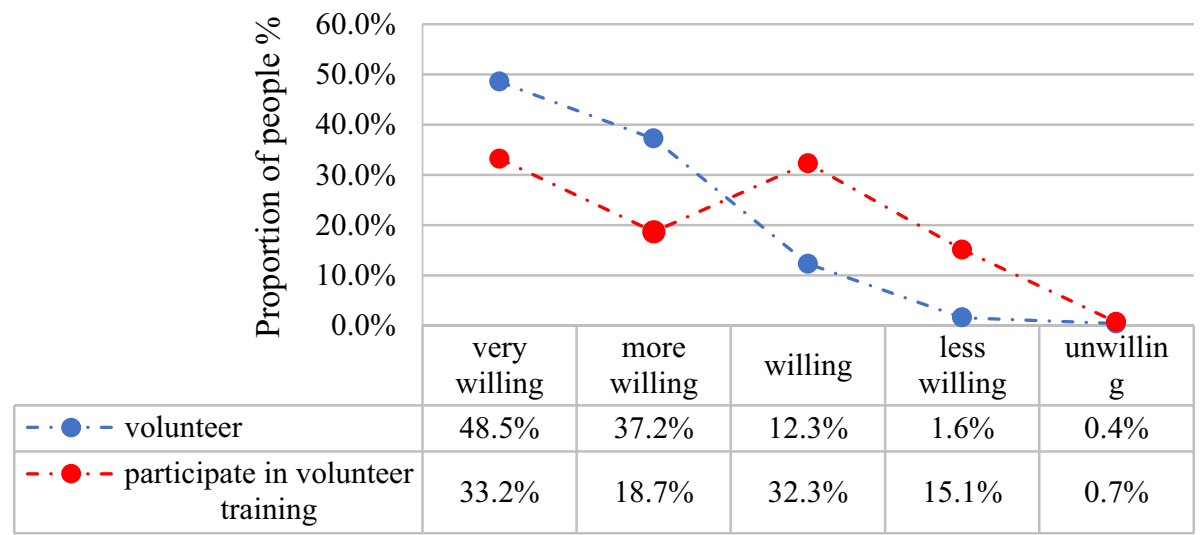

Fig. 6 Participant's willingness to severe as a volunteer and participate in volunteer training

More than half of the public are very willing to assist the government in post-disaster property statistics. Only $2 \%$ of the public are unwilling or less willing to assist. It can also be seen that participant's disaster prevention intentions are very strong as nearly $60 \%$ are very willing to take on the responsibility of self-rescue and mutual rescue work. And only $1.6 \%$ of participants were less willing or unwilling to undertake self-rescue and mutual rescue work. Furthermore, participant's willingness to participate in disaster reduction work is also very strong, reaching $60.4 \%$. Only $1.5 \%$ of participants are less willing or unwilling to participate in the community's disaster reduction work.

\subsubsection{People's willingness to severe as a volunteer to help affected areas and participate in disaster relief volunteer training in their spare time}

In summary, participant's willingness to become a volunteer is very strong. As shown in Fig. 6, Over $85 \%$ of participants are very willing or more willing to severe as a volunteer. Only $2 \%$ of participants are less willing or unwilling to become a volunteer to help the affected areas. Moreover, over 50\% of participants are very willing or more willing to participate in volunteer training in their spare time. The proportion of participants who are very willing $(33.2 \%)$ and willing $(32.3 \%)$ to participate in volunteer training show only a

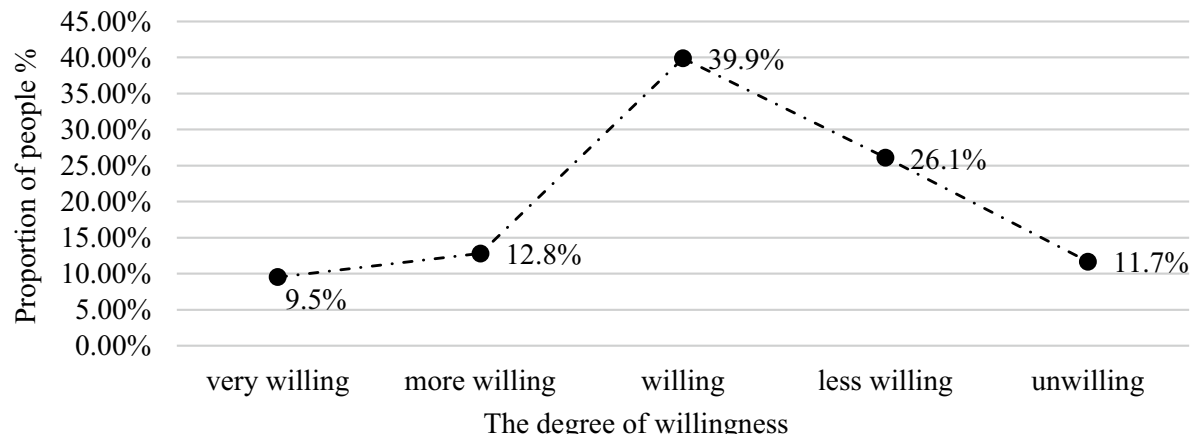

Fig. 7 Participant's willingness to master skills of disaster reduction and rescue 


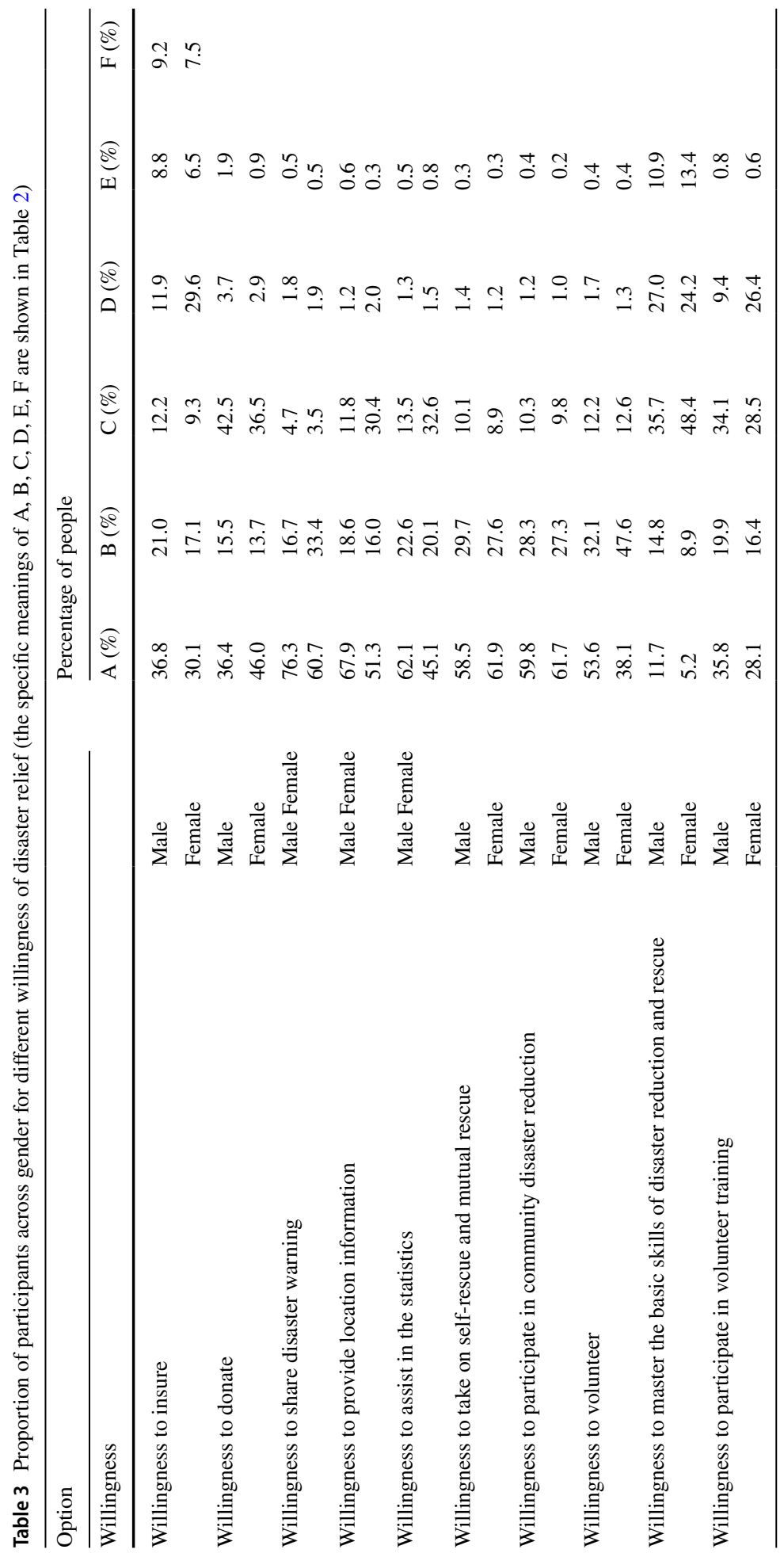


small difference. Also, less than $16 \%$ of the public are less willing or unwilling to participate in volunteer training.

\subsubsection{People's willingness to master the basic skills of disaster reduction and rescue}

As shown in Fig. 7, only $9.5 \%$ and $12.8 \%$ of participants are very willing or more willing to master disaster reduction and rescue skills, and over $37 \%$ of the public are less willing or unwilling to master disaster reduction and rescue skills. This highlights that participants are not active in developing disaster reduction and rescue skills.

\subsection{Difference in gender of participant's willingness of disaster relief}

Gender differences across 10 aspects related to disaster relief are provided in Table 3.

From Table 3, we can derive some meaningful conclusions. Firstly, the public's awareness of insurance can be further improved. Many participants are only willing to insure within 100 Yuan (14.8 USD). Moreover, women are more active in insuring for meteorological disasters when compared with men. It can be illustrated that both men and women are willing to insure within the price range of 100-300 Yuan (14.8 to 44.3 USD). However, when the amount of insurance increases to 400-500 Yuan (59.0 to 73.8 USD), men $(11.9 \%)$ and women $(29.6 \%)$ show larger differences. The proportion of men and women who are willing to insure 500-600 Yuan (73.8 to 88.5 USD) and above 600 Yuan (88.5 USD) are similar but keep the smaller value. Further analyzing the participant's willingness of donation, an obvious fact is that majority of participants were very willing to donate to the affected areas. More than half of men and nearly $60 \%$ of women are very willing or more willing to donate. Only less than $10 \%$ are less willing and unwilling to donate. It can also be seen that both men and women are generally very willing to share disaster warning information with their relatives and friends. As many as $76.3 \%$ of the men and $60.7 \%$ of the women are very willing to share warning information. In addition, women are twice as likely to share warning information as compared to men. The proportion of participants who are less willing and unwilling to share are both less than $5 \%$.

Then, it can also be seen that more than half of men and women are very willing to cooperate with the government's disaster prevention work and provide location information to the government's disaster reduction system, especially for men (67.9\%). In other situations, the proportion of women who are willing to provide location information are more than twice as that of men. Quite few (both less than 3\%) are less willing and unwilling to provide location information. In total, the willingness of men and women to provide location information shows extremely small difference with the Pearson correlation coefficients of 0.9 .

It is also shown that although everyone is willing to cooperate with the government to carry out post-disaster property statistics, men are more willing to cooperate with the government's property statistics than women. The proportion of men $(62.1 \%)$ who are very willing to cooperate is $17 \%$ higher than that of women (45.1\%). However, the proportion of women (32.6\%) who are willing to assist in the post-disaster statistics are more than twice the proportion of men (13.5\%). Extremely few (both less than $2 \%$ ) are less willing or unwilling to cooperate with government. In total, there is very small difference with the Pearson correlation coefficients near 0.9 in the willingness of men and women to assist government in the post-disaster statistics. 


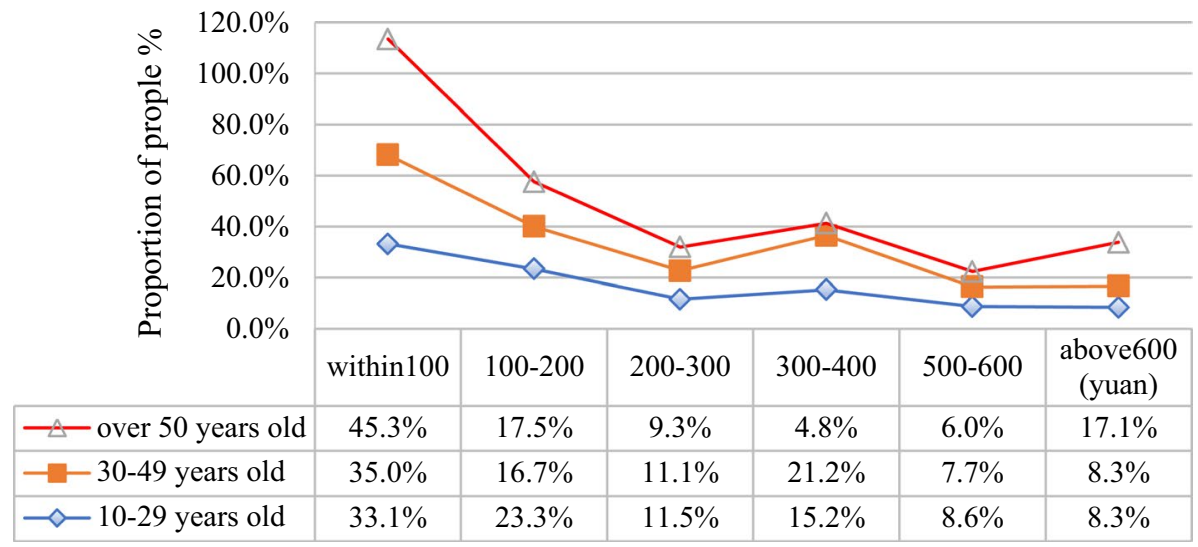

Fig. 8 The distribution of participant's willingness of insurance across all age

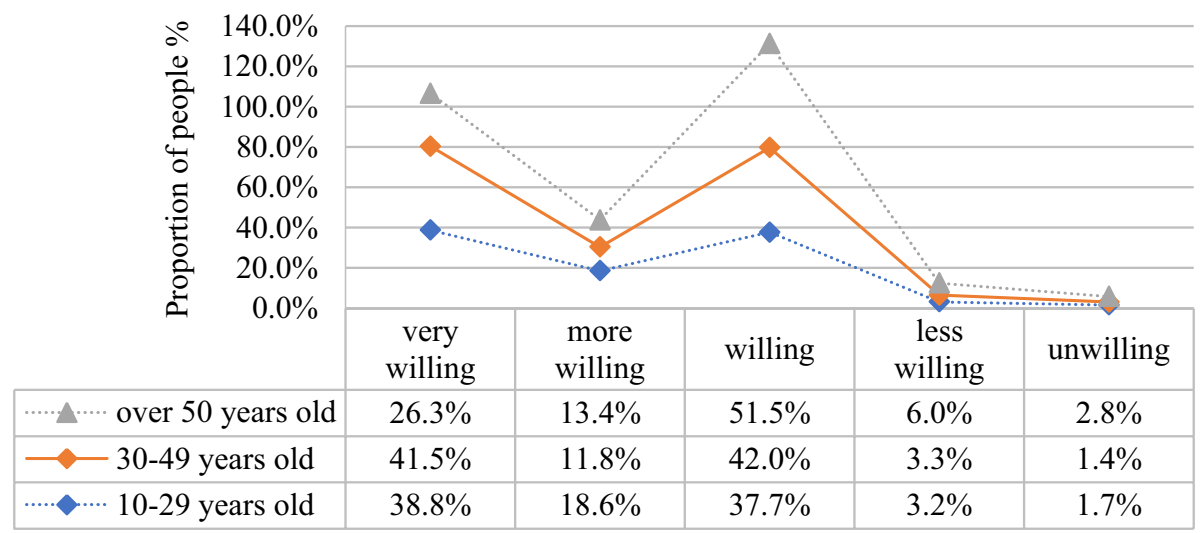

Fig. 9 Participant's willingness to donate among all age

Thirdly, participants have a stronger willingness to take responsibility for disaster prevention, self-rescue, mutual rescue, and participate in community disaster reduction. Generally, there is no significant difference with the Pearson correlation coefficients close to 1 between men and women in their willingness to take disaster prevention and self-rescue, as well as community disaster reduction work. About $60 \%$ of men and women are very willing to take on self-rescue and participate in disaster reduction. The less than $2 \%$ are less willing or unwilling to undertake self-rescue and community disaster reduction. Furthermore, most participants are willing to become a volunteer for helping affected areas. Over $85 \%$ of men and women are very willing and more willing to be a volunteer. Among them, the proportion of men who are very willing to be volunteer is $15.5 \%$ more than that of women. Only about $2 \%$ of men and women are less willing and unwilling to be a volunteer. 


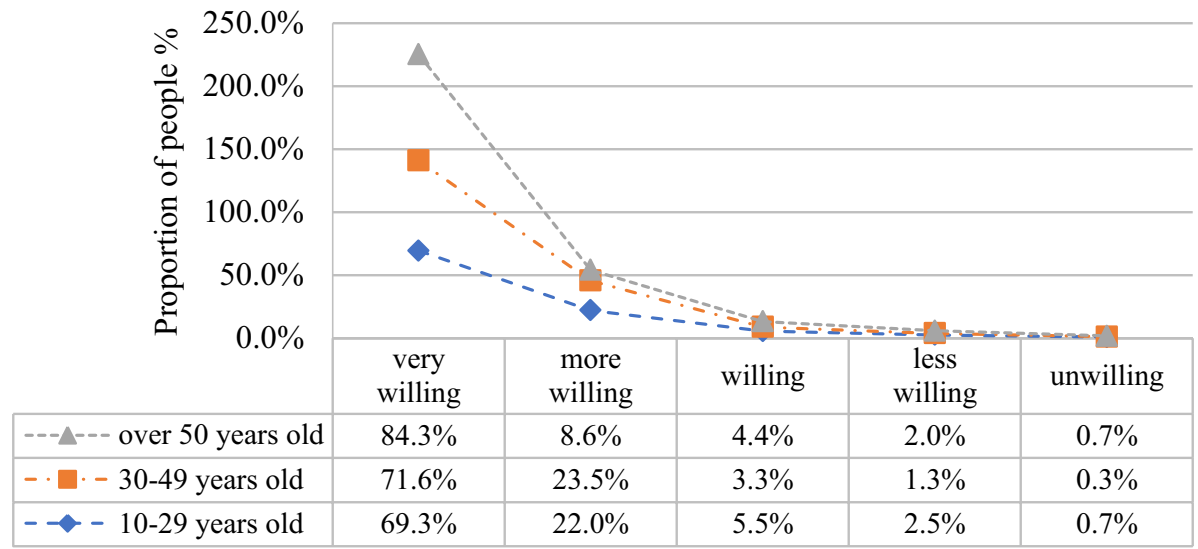

Fig. 10 Participant's willingness among all age to share disaster warning information

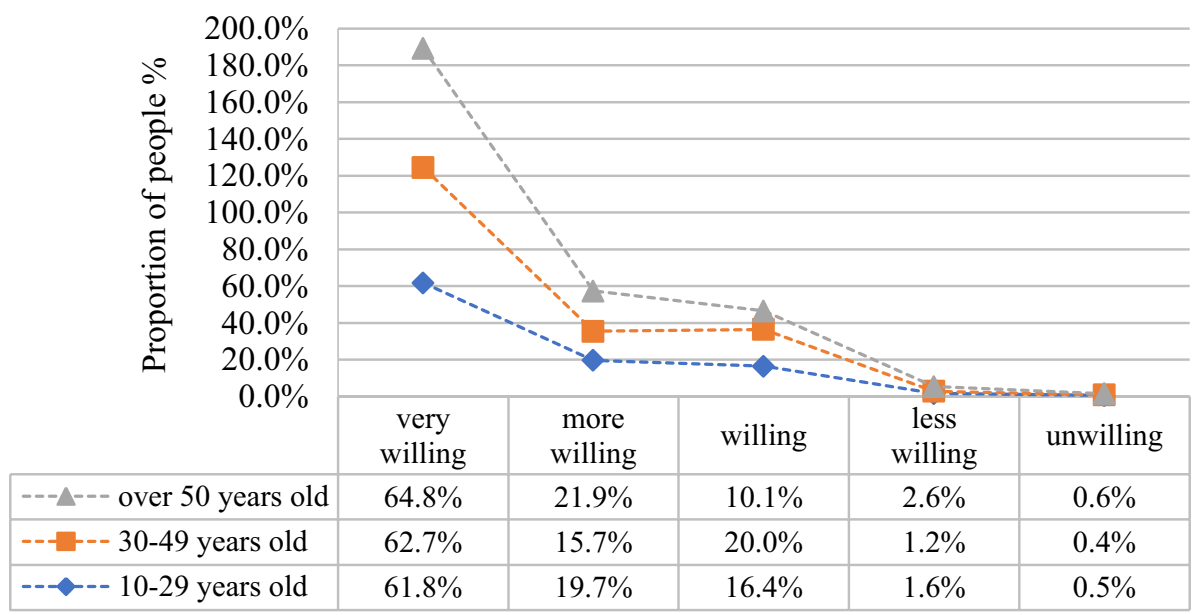

Fig. 11 The public's willingness among all age to provide location information

Finally, men and women in general are not very willing to master the basic skills of disaster reduction and rescue, and women are less willing to master the basic skills of disaster relief when compared with men. Almost $38 \%$ of men and women are less willing or unwilling to master the basic skills of disaster reduction and rescue. There are only $26.5 \%$ of men who are very willing or more willing to master the basic skills of disaster reduction and rescue. That is higher than $14.1 \%$ of women. However, the larger proportion of the men (55\%) and women (44.5\%) are very willing or more willing to participate in volunteer training of disaster relief in their spare time. Women (26.4\%) have less willingness to participate in volunteer training of disaster relief than men $(9.4 \%)$. In addition, $27 \%$ of women are less willing or unwilling to participate in volunteer training in their spare time, more than twice the proportion of men $(10.2 \%)$. 


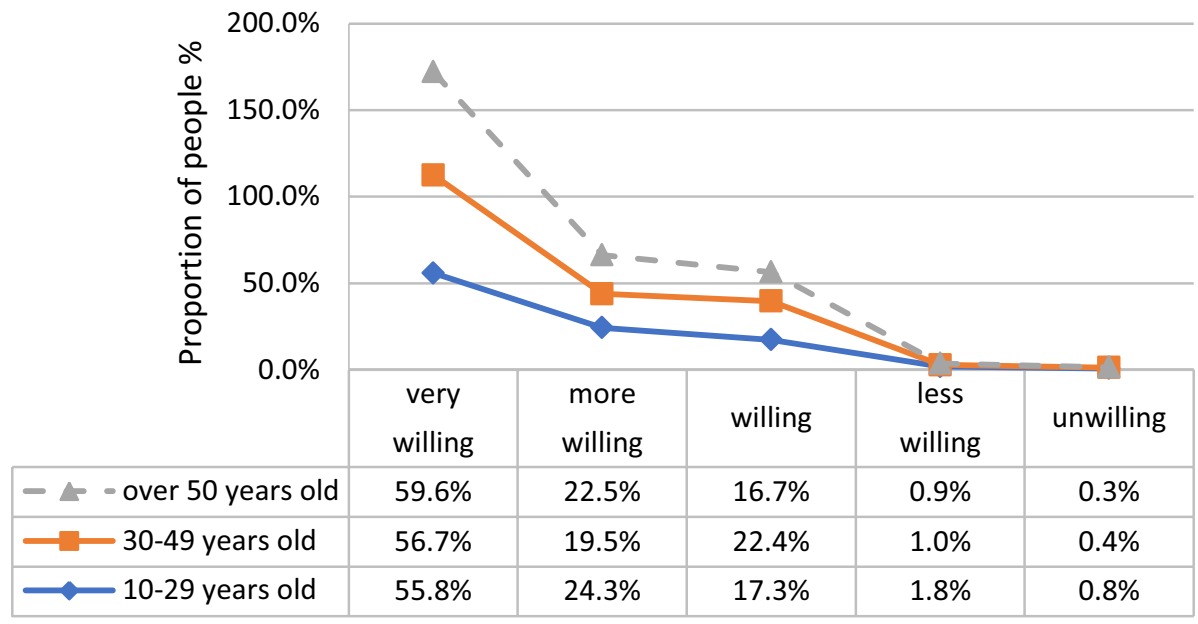

Fig.12 The public's willingness to assist in post-disaster property statistics among all ages

\subsection{Difference in Age for participant's willingness of disaster relief}

The analysis of difference in age for participant's willingness of disaster relief from 10 aspects is shown in Figs 8, 9, 10, 11, and 12.

\subsubsection{The distribution of participant's willingness of insurance across different ages}

Participant's willingness to insure for meteorological disasters is not strong, as most of the participants are willing to insure within 100 Yuan (14.8 USD). Compared with young people, the old are more willing to pay high prices for meteorological disasters. As shown in Fig. 8, the largest category for three age groups was a preference to insure within 100 Yuan (14.8 USD), accounting for 33.1\% among people aged 10-29 years old, $35 \%$ among people aged $30-49$ years old, $45.3 \%$ among people over 50 years old. However, the gap between the proportion of the public for three age groups who are willing to insure between 200 and 300 (29.5 to 44.3 USD) and 500 and 600 Yuan (73.8 to 88.5 USD) is very small. In addition, we can see that $17.1 \%$ of the public over 50 years old are willing to insure for more than 600 Yuan (88.5 USD).

\subsubsection{Participant's willingness to donate among all age}

Most of the participants among all age groups are willing to donate. But the willingness to donate among the elderly is not strong as other age groups. As shown in Fig. 8, 53.3\% of participants aged $30-49$ and $57.4 \%$ of participants aged 10-29 years old are very willing or more willing to donate. Only $39.7 \%$ of participants over 50 years old are very willing or more willing to donate. The proportion of participants over 50 years old who are less willing or unwilling to donate is close to twice the proportion of participants in the other two age groups. 


\subsubsection{Participants willingness among all age to share disaster warning information}

Overall, people among all age groups are willing to share disaster warning information. As shown in Fig. 10, most of participants among all age groups are very willing to share disaster warning with relatives and friends. Their percentages reach $69.3 \%$ among the young aged 10-29 years, $71.6 \%$ among people aged 30-49 years, $84.3 \%$ among the elderly over 50 years old. In addition, $8.6 \%$ of the elderly over 50 years old are more willing to share, and the proportion of other two ages with more willingness to share close to $25 \%$. For all ages, less than $3 \%$ of participants are less willing or unwilling to share disaster warning information.

\subsubsection{Participant's willingness among all age to provide location information}

It can be seen that the public among all age are very willing to provide location information to cooperate with the government, in order to avoid casualties as much as possible. As shown in Fig. 11, the public's willingness to provide location information among all age groups is similar, and over $60 \%$ of each group are very willing to provide location information to the government. Moreover, the proportion of the elderly over 50 who are more willing to provide location information is slightly larger than the other two age groups. In addition, less than $3 \%$ of each group is less willing and unwilling to provide location information.

\subsubsection{Participants willingness among all age to assist in post-disaster property statistics}

Participants of each age group are very willing to assist the government with post-disaster statistics work. At the same time, there is no significant difference in public's willingness across all age groups. As shown in Fig. 12, over half of the participants across three age groups are very willing to assist the government in post-disaster property statistics work (55.8\% participants aged 10-29 years old, 56.7\% participants aged 30-49 years old, 59.6\% participants over 50 years old). Less than $3 \%$ of each age group is less willing or unwilling to assist in the statistic.

\subsection{Correlation analysis of the participant's willingness among different age}

We calculated the Pearson correlation coefficient of participant's willingness between different age groups in six major aspects. The correlations are presented in Table 4.

From Table 4, participants in different ages show no difference in four aspects (coefficients $>0.95, P$ value $<0.05$ ), except for the willingness to donate and to master the basic skills of disaster reduction and rescue. In particular, participants aged 10-29 and above 50 years old whose willingness to participate in community disaster reduction has no difference and their correlation coefficients are 1. Also participants aged 10-29 and 30-49 years old whose willingness to donate has extremely small difference and their correlation coefficients are 0.98 . However, for participants in other age groups there is a slight difference in the willingness to donate. Most people aged 10-29 years old are very willing to donate, but people aged above 50 years old are only willing to donate. There is little difference in the participants aged 10-29 and 30-49 years old whose willingness to master the basic skills of disaster reduction and rescue (coefficients $=0.99$ ). However, participants aged 10-29 and above 


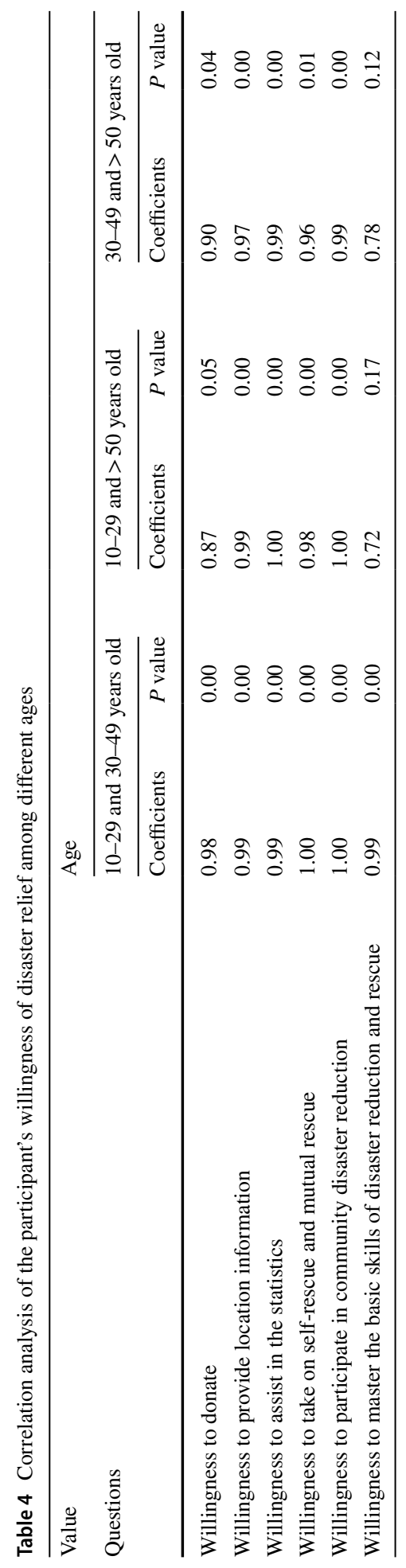


50 years old, 30-49, and above 50 years old have some differences in willingness to master the basic skills of disaster reduction. That Pearson correlation coefficients are, respectively, 0.72 and 0.78 . This is because the participants aged 10-29 and 30-49 years old are mostly willing to master relevant skills of disaster reduction and rescue, while the largest number of the participants aged above 50 years old is less willing to master such skills.

\section{Conclusion and discussion}

\subsection{Conclusion}

This study investigated the willingness of the public to engage with disaster relief efforts across different gender and age groups in China. In total 62,903 respondents were investigated which were comprised of $67 \%$ males and $33 \%$ females. Furthermore, among 62,903 respondents, $50.7 \%$ of respondents were between the ages 30 and 49 and $44.8 \%$ respondents were between 10 and 29 years old. The study analyzed the differences and correlations between different gender and age groups. The results show that there are larger differences in the willingness of insuring between male and females, as well as across different age groups when the amount of insurance reaches above 300 Yuan (44.3 USD). Furthermore, the study also found differences among age groups related to the willingness of donating money and mastering the basic skills of disaster reduction and rescue. However, aside from these differences there were few other variances.

\subsection{Discussion}

Although there are some studies which discuss the public's willingness to obtain insurance in the context of natural disasters there is very little research examining other kinds of activities citizens would engage in to help disaster relief efforts. Our investigation from 62,903 respondents in China has revealed the general picture of 10 areas related to the public's readiness and personal actions that can be taken to mitigate natural hazard risks. The costs of disaster reduction (Luo et al. 2013) and an individual's insurance experience and opinion on the value of insurance (Wang et al. 2012) can positively influence their mitigation intentions related to natural hazards. Furthermore, social economic aspects, risk perception, and social trust can also have a positive influence on the mitigation intentions related to natural hazards (Lin et al. 2008).

Insurance can mitigate residents' costs of evacuation from natural hazards. However, most respondents would not purchase an insurance product even at the lowest price (Whitehead et al. 2006). It was also found that, in China, the public's awareness of insurance is not high. More than half of participants are only willing to insure within a 200 Yuan $(29.5$ USD) price range, and a small number (17\%) are willing to insure over 500 Yuan (73.8 USD). Moreover, there are larger differences in the readiness to obtain insurance between men and women. It was found that women (29.6\%) were more willing to insure for larger amounts of money compared to men (11.9\%). It was also found that when compared with young people older citizens were willing to pay more for insurance.

Voluntary donations are regarded as one of the major sources for public goods provision across different countries in the world. Natural disasters and climatic change are major threats for many countries in the world, and disaster mitigation planning and 
implementation cannot be sustainable without the cooperation of citizens as well as their voluntary participation and donation (Pearce 2003). Moreover, it was found that the public's willingness to donate to affected areas is low, but their willingness to share disaster warning information is high. The proportion of participants who were very willing to donate during a disaster was less than $40 \%$. However, more respondents (71\%) were very willing to share disaster warning information with relatives and friends. The number of respondents (22\%) who are more willing to share is also at a good level.

Moreover, it was found that females are more willing to donate than males and those over 50 years old are less positive toward donating compared to younger participants. Our findings are in line with existing research conducted in Bangladesh, which found that age, education, and income can play a vital influence on residents' willingness to donate. This is because usually those who are well-off are more willing to donate money for affected areas (Shahrier et al. 2019). However, our findings on the differences among age groups are not consistent with that of past literature in Europe which has found that financial donations increase by age group (Bauer et al. 2013). It is quite plausible that young respondents are expected to live longer, so they may have stronger incentives to make investments for reducing future loss from natural disasters (Menchik et al. 1987). Another study also found that young people take more personal responsibility toward climate change (Yu et al. 2013).

Thirdly, the sharing of information before and during disasters can help mitigate the panic of citizens and strengthen their response ability to natural hazards (Helsloot et al. 2004). It was found that the public in China are very willing to provide personal location information and assist the government in post-disaster property statistics. Only a small percentage of $1.9 \%$ of participants were less willing or unwilling to provide personal location information, and only $2 \%$ were unwilling or less willing to assist property statistics work from government. Men are more willing to assist the government and provide location information in comparison with women. Furthermore, participants across different ages showed similarities regarding their willingness to assist the government and provide location information.

Finally, the public are enthusiastic to participate in disaster relief. More than $80 \%$ of participants are willing to take on self-rescue and disaster reduction within the community. This category was also found that there was only a small difference between gender and age. However, surprisingly, it was found that victims who have suffered from flood and landslide are less willing to take risk mitigation measures than the general public (Lin et al. 2008). Furthermore, our investigation also found that the public were not actively engaged in developing disaster reduction and rescue skills. They did not have more willingness to participate in volunteer training in their spare time, and this was especially the case for females.

Based on the conclusions above, the following recommendations are put forward:

(1) The government should strengthen the education and publicity of climate disaster insurance to raise the public's awareness of obtaining insurance. This could be more strongly targeted toward men and the public aged 10-49 years old as these groups were least positive toward insurance.

(2) It is essential to improve the climate monitoring system and enhance the accuracy of disaster warning information. The public are very willing to share disaster warning information, so the government should closely cooperate with the public to expand the collection and coverage of information. 
(3) The public are very enthusiastic to participate in disaster relief and very willing to provide personal location information and assist the government in post-disaster property statistics. Henceforth, the government should improve the level and scope for public to participate in climate disaster prevention.

(4) The public are very willing to take on disaster relief work but are not active in volunteer training, so the government should actively enhance the public's knowledge of climate disasters and strengthen volunteer training through adding incentives to attract the public and develop interesting training courses.

Supplementary information The online version of this article (https://doi.org/10.1007/s11069-021-04538 $-7)$.

Acknowledgements This study was supported by the Major Program of National Social Science Fund of China "study on emergency management of meteorological disaster based on big data fusion" (Grant No. 16ZDA047).

Funding This work of survey was supported and funded by the Major Program of National Social Science Fund of China "Study on emergency management of meteorological disaster based on big data fusion" (Grant No. 16ZDA047).

\section{Compliance with ethical standards}

Conflict of interest It is hereby declared by the authors that there is no conflict of interests.

Open Access This article is licensed under a Creative Commons Attribution 4.0 International License, which permits use, sharing, adaptation, distribution and reproduction in any medium or format, as long as you give appropriate credit to the original author(s) and the source, provide a link to the Creative Commons licence, and indicate if changes were made. The images or other third party material in this article are included in the article's Creative Commons licence, unless indicated otherwise in a credit line to the material. If material is not included in the article's Creative Commons licence and your intended use is not permitted by statutory regulation or exceeds the permitted use, you will need to obtain permission directly from the copyright holder. To view a copy of this licence, visit http://creativecommons.org/licenses/by/4.0/.

\section{References}

Adiyoso W, Kanegae H (2013) The preliminary study of the role of islamic teaching in the disaster risk reduction (A qualitative case study of Banda Aceh, Indonesia). Proced Environ Sci 17:918-927

Arshad M, Amjath-Babu TS, Kächele H, Müller K (2016) What drives the willingness to pay for crop insurance against extreme weather events (flood and drought) in Pakistan? A hypothetical market approach. Clim Dev 8(3):234-244

Bauer TK, Bredtmann J, Schmidt CM (2013) Time vs. money-the supply of voluntary labor and chritatable donations across Europe. Eur J Polit Econ 32:80-94

EM-DAT: The Emergency Events Database. https://public.emdat.be/. Accessed 1 June 2020

Emergency Warning System-A new service to protect life. https://www.jma.go.jp/jma/en/Emergency_ Warning/Leaflet(Emergency_Warning_System).pdf. Accessed 6 June 2020

Grothmann T, Reusswig F (2006) People at risk of flooding: why some residents take precautionary action while others do not. Nat Hazards 38:101-120

Helsloot I, Ruitenberg A (2004) Citizen response to disasters: a survey of literature and some practical implications. J Conting Crisis Manag 12(3):98-111

Hillier D (2018) Facing risk: options and challenges in ensuring that climate/disaster risk finance and insurance deliver for poor people. https://oxfamilibrary.openrepository.com/bitstream/handle/10546/62045 7/bp-facing-risk-climate-disaster-insurance-160418-en.pdf?sequence $=13$ 
Juanzon JBP, Oreta AWC (2018) An assessment on the effective preparedness and disaster response: the case of Santa Rosa City, Laguna. Proced Eng 212:929-936

Kreibich H, Bubeck P, Kunz M et al (2014) A review of multiple natural hazards and risks in Germany. Nat Hazards 74:2279-2304

Li J, Wu W, Ye X et al (2019) Innovative trend analysis of main agriculture natural hazards in China during 1989-2014. Nat Hazards 95:677-720

Lin S, Shaw D, Ho M (2008) Why are flood and landslide victims less willing to take mitigation measures than the public? Nat Hazards 44(2):305-314

Liu CS, Xu HQ (2018) Preliminary analysis and policy recommendations on climate safety issues. Macroecon Manag 2:49-55 ((in Chinese))

Luo X, Levi AE (2013) Factors influencing willingness to participate in disaster reduction. Nat Hazards 66(2):1243-1255

McClelland GH, William DS, Don LC (1993) Insurance for low-probability hazards: a bimodal response to unlikely events. J Risk Uncertain 7(1):95-116

Menchik PL, Weisbrod BA (1987) Volunteer labor supply. J Public Econ 32:159-183

Natural disasters 2019. https://www.emdat.be/publications. Accessed 6 July 2020

Ngoc QAN, Thanh BP, Dang TT (2019) Willingness to pay for agricultural flood insurance in the Mekong River Delta. Environ Hazards 18:212-227

O'Neill E, Brereton F, Shahumyan H, Clinch JP (2016) The impact of perceived flood exposure on flood-risk perception: the role of distance: flood-risk perception: the role of distance. Risk Anal 36(11):2158-2186

Owusu S, Wright G, Arthur S (2015) Public attitudes towards flooding and property-level flood protection measures. Nat Hazards 77(3):1963-1978

Pearce L (2003) Disaster management and community planning, and public participation: how to achieve sustainable hazard mitigation. Nat Hazards 28(2-3):211-228

Roder G, Hudson P, Tarolli P (2019) Flood risk perceptions and the willingness to pay for flood insurance in the Veneto region of Italy. Int J Disaster Risk Reduct 37:101-172

Samaddar S, Yokomatsu M, Dayour F et al (2015) Evaluating effective public participation in disaster management and climate change adaptation: insights from Northern Ghana through a user-based approach: evaluating effective public participation in disaster management. Risk Hazards Crisis Public Policy 6(1):117-143

Schneider Robert O (2011) Climate change: an emergency management perspective. Disaster Prev Manag 20(1):53-62

Shah AA, Shaw R, Ye J et al (2019) Current capacities, preparedness and needs of local institutions in dealing with disaster risk reduction in Khyber Pakhtunkhwa, Pakistan. Int J Disaster Risk Reduct 34:165-172

Shahrier S, Kotani K (2019) Natural disaster mitigation through voluntary donations in a developing country: the case of Bangladesh. Environ Econ Policy Stud 21(1):37-60

The Hyogo Framework for Action (HFA) 2005-2015: Building the Resilience of Nations and Communities to Disasters. https://www.wmo.int/pages/prog/drr/documents/HFA_highlighted.pdf. Accessed 15 July 2020

The Sendai Framework for Disaster Risk Reduction 2015-2030. https://www.wcdrr.org/preparatory/post2 015. Accessed 15 July 2020

Wang M, Liao C, Yang S et al (2012) Are people willing to buy natural disaster insurance in China? Risk awareness, insurance acceptance, and willingness to pay: are people willing to buy natural disaster insurance in China? Risk Anal 32(10):1717-1740

Whitehead JC (2006) Willingness to pay for low probability, low loss hazard insurance. https://core.ac.uk/ download/pdf/7080153.pdf

$\mathrm{Xu}$ X (2019) Prospects for disaster management in China and the role of insurance. Environ Hazards 18(3):1-17

Yu H, Wang B, Zhang Y et al (2013) Public perception of climate change in China: results from the questionnaire survey. Nat Hazards 69(1):459-472

Zhang M, Chen Y, Wu X (2019) Resident preferences for augmented rainstorm disasters management strategies: the case of Nanjing in China. Environ Hazards 18(1):78-92

Zhong S, Okiyama M, Tokunaga S (2014) Impact of natural hazards on agricultural economy and food production in china: based on a general equilibrium analysis. J Sustain Dev 7(2):45-69

Publisher's Note Springer Nature remains neutral with regard to jurisdictional claims in published maps and institutional affiliations. 